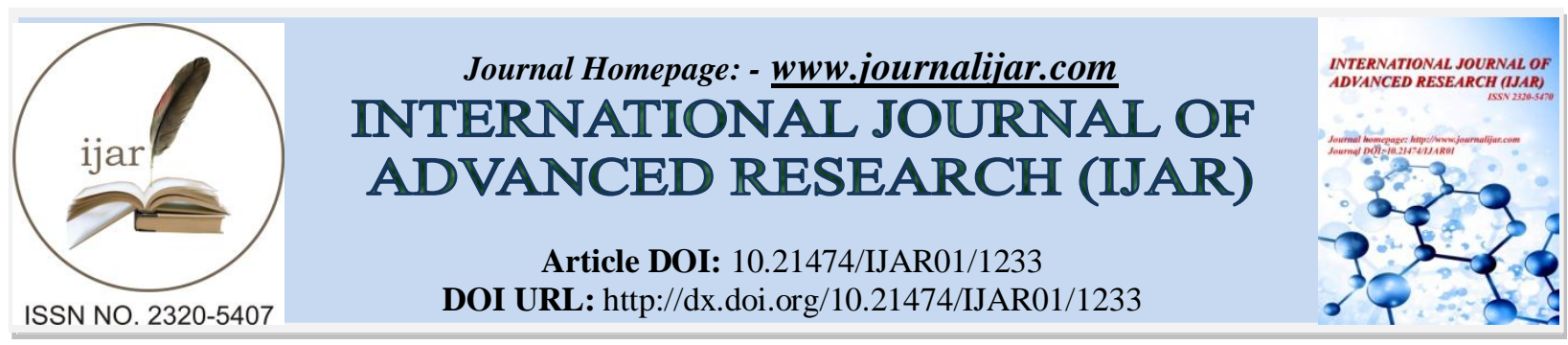

RESEARCH ARTICLE

\title{
NUMERICAL SOLUTION OF COUPLED FREDHOLM INTEGRAL EQUATIONS OF SECOND KIND USING HAAR WAVELETS.
}

Sumana R. Shesha, Savitha S. and Achala L. Nargund.

P. G. Department of Mathematics and Research Centre in Applied Mathematics, M. E. S. College of Arts, Commerce and Science, $15^{\text {th }}$ cross, Malleswaram, Bangalore - 560003.

\section{Manuscript Info}

Manuscript History

Received: 18 June 2016

Final Accepted: 29 July 2016

Published: August 2016

Key words:-

Integral equation, one-dimensional coupled Fredholm integral equation of second kind, two-dimensional coupled Fredholm integral equation of second kind, Haar wavelets, collocation points.

\begin{abstract}
Integral equations provide an important tool for modeling numerous phenomena and processes. In this paper, we use Haar wavelets to solve one-dimensional and two-dimensional coupled Fredholm integral equations of second kind. This method converts the system of linear integral equations into a system of linear algebraic equations. The numerical results are compared with the exact solution to prove the accuracy of the Haar wavelet method.
\end{abstract}

Copy Right, IJAR, 2016,. All rights reserved.

\section{Introduction:-}

Fredholm integral equations are widely used in mechanics, geophysics, electricity and magnetism, kinetic theory of gases, hereditary phenomena in biology, quantum mechanics, mathematical economics, and queuing theory. Babolian and Mordad [1] used hat basis functions for solving systems of linear and nonlinear integral equations of the second kind. Khalil and Khan [2] used Legendre polynomials for solving coupled system of Fredholm integral equations. Rashidinia and Zarebnia [3] used Sinc collocation method to obtain an approximate solution of system of Fredholm integral equations and also established the exponential rate of convergence of the method. Maleknejad et. al. [4] used collocation method with Legendre polynomials for solving system of integral equations. Ibraheem [5] solved system of linear Fredholm integral equations of second kind using open Newton-Cotes formulas. Sahu and Ray [6] applied semi-orthogonal B-spline wavelet collocation method to obtain a numerical solutions for the system of Fredholm integral equations of second kind. Vahidi and Damercheli [7] solved systems of linear Fredholm integral equations of the second kind using modified Adomian decomposition method. Ebrahimi and Rashidinia [8] used spline collocation for solving system of Fredholm and Volterra integral equations.

Numerical solutions for solving single two-dimensional Fredholm integral equation have been treated using different methods. Hanson and Phillips [9] presented a general procedure for numerically solving linear Fredholm integral equations of the first kind in two integration variables. The method involves collocation followed by the solution of an appropriately scaled stabilized matrix least squares problem. Carutasu [10] obtained the numerical solution of two-dimensional nonlinear Fredholm integral equations of the second kind by Galerkin and iterated Galerkin method using spline functions. Han and Wang [11] used discrete Galerkin and iterated discrete Galerkin method to study the numerical solution of two-dimensional Fredholm integral equation. Ismail [12] used mechanical quadrature method to solve two-dimensional nonlinear singular integral equation with Hilbert kernel. Saeed and

Corresponding Author:- Sumana R. Shesha.

Address:- P. G. Department of Mathematics and Research Centre in Applied Mathematics, M. E. S.

College of Arts, Commerce and Science, $15^{\text {th }}$ cross, Malleswaram, Bangalore - 560003. 
Mahmud [13] applied two-dimensional quadrature methods to find the approximate solution for a system of twodimensional linear Fredholm integral equation of the second kind.

In this paper, one-dimensional and two-dimensional coupled Fredholm integral equations of second kind are solved using Haar wavelet collocation method. The Haar wavelet is the principal known wavelet and was proposed in 1909 by Alfred Haar. The Haar wavelet is likewise the least complex conceivable wavelet. Over the recent decades, wavelets by and large have picked up a respectable status because of their applications in different disciplines and in that capacity have numerous examples of overcoming adversity. Prominent effects of their studies are in the fields of signal and image processing, numerical analysis, differential and integral equations, tomography, and so on. Sumana and Achala [14] have given a brief report on Haar wavelets. The paper is organized as follows. The Haar wavelet preliminaries and the function approximation are presented in Section 2. The method of solution is proposed in Section 3. The numerical examples and discussions are presented in Section 4. The conclusions drawn are presented in Section 5.

\section{Haar Wavelets:-}

The Haar wavelet family for $x \in[0,1]$ is defined [15] as follows

$$
h_{i}(x)=\left\{\begin{array}{cc}
1 & \text { for } x \in\left[\xi_{1}, \xi_{2}\right) \\
-1 & \text { for } x \in\left[\xi_{2}, \xi_{3}\right) \\
0 & \text { elsewhere }
\end{array}\right.
$$

where

$$
\xi_{1}=\frac{k}{m}, \xi_{2}=\frac{k+0.5}{m}, \xi_{3}=\frac{k+1}{m}
$$

Here $m=2^{b}, b=0,1, \ldots, J$ indicates the level of the wavelet; $k=0,1, \ldots, m-1$ is the translation parameter. $J$ is the maximum level of resolution. The index $i$ in equation (1) is calculated by the formula $i=m+k+1$. In the case of minimum values $m=1, k=0$ we have $i=2$. The maximum value of $i$ is $i=2 M=2^{J+1}$. For $i=1$ ,$h_{1}(x)$ is assumed to be the scaling function which is defined as follows.

$$
h_{1}(x)=\left\{\begin{array}{lc}
1 & \text { for } x \in[0,1) \\
0 & \text { elsewhere }
\end{array}\right.
$$

Any function $f(x)$ defined on $[0,1]$ can be expressed in terms of Haar wavelets as follows.

$$
f(x)=\sum_{i=1}^{2 M} a_{i} h_{i}(x)
$$

where the wavelet coefficients $a_{i}, i=1,2, \ldots, 2 M$ are to be determined.

Any function $f(x, y)$ defined on $[0,1] \times[0,1]$ can be expressed in terms of Haar wavelets as follows.

$$
f(x, y)=\sum_{i=1}^{2 M} \sum_{j=1}^{2 M^{*}} a_{i j} h_{i}(x) h_{j}(y),
$$

where the wavelet coefficients $a_{i j}, i=1,2, \ldots, 2 M, j=1,2, \ldots, 2 M^{*}$ are to be determined. Here, $h_{j}(y)$ is defined as follows.

$$
h_{j}(y)=\left\{\begin{array}{cc}
1 & \text { for } y \in\left[\eta_{1}, \eta_{2}\right) \\
-1 & \text { for } y \in\left[\eta_{2}, \eta_{3}\right) \\
0 & \text { elsewhere }
\end{array}\right.
$$


where

$$
\eta_{1}=\frac{k^{*}}{m^{*}}, \eta_{2}=\frac{k^{*}+0.5}{m^{*}}, \eta_{3}=\frac{k^{*}+1}{m^{*}} .
$$

Here $m^{*}=2^{b^{*}}, b^{*}=0,1, \ldots, J^{*}$ indicates the level of the wavelet; $k^{*}=0,1, \ldots, m^{*}-1$ is the translation parameter. $J^{*}$ is the maximum level of resolution. The index $j$ in equation (6) is calculated by the formula $j=m^{*}+k^{*}+1$. In the case of minimum values $m^{*}=1, k^{*}=0$ we have $j=2$. The maximum value of $j$ is $j=2 M^{*}=2^{J^{*}+1}$.

\section{Method of Solution:-}

\section{One-dimensional Coupled Fredholm Integral Equations:-}

The one-dimensional coupled Fredholm integral equations of the second kind are given by

$$
\begin{aligned}
& u(x)=f_{1}(x)+\int_{0}^{1} k_{1}(x, t) u(t) d t+\int_{0}^{1} k_{2}(x, t) v(t) d t \\
& v(x)=f_{2}(x)+\int_{0}^{1} k_{3}(x, t) u(t) d t+\int_{0}^{1} k_{4}(x, t) v(t) d t
\end{aligned}
$$

where $f_{1}(x), f_{2}(x)$ are known functions, $k_{1}(x, t), k_{2}(x, t), k_{3}(x, t), k_{4}(x, t)$ are the kernels and $u(x), v(x)$ are the unknown functions.

Let the Haar wavelet solutions be in the form

$$
\begin{aligned}
& u(x)=\sum_{i=1}^{2 M} a_{i} h_{i}(x) \\
& v(x)=\sum_{i=1}^{2 M} b_{i} h_{i}(x)
\end{aligned}
$$

Substituting equations (10) and (11) in equations (8) and (9) gives

where

$$
\begin{aligned}
& \sum_{i=1}^{2 M}\left\{a_{i}\left[h_{i}(x)-\alpha_{i}(x)\right]-b_{i} \beta_{i}(x)\right\}=f_{1}(x) \\
& \sum_{i=1}^{2 M}\left\{b_{i}\left[h_{i}(x)-\psi_{i}(x)\right]-a_{i} \phi_{i}(x)\right\}=f_{2}(x)
\end{aligned}
$$

$$
\begin{aligned}
& \alpha_{i}(x)=\int_{0}^{1} k_{1}(x, t) h_{i}(t) d t \\
& \beta_{i}(x)=\int_{0}^{1} k_{2}(x, t) h_{i}(t) d t \\
& \phi_{i}(x)=\int_{0}^{1} k_{3}(x, t) h_{i}(t) d t \\
& \psi_{i}(x)=\int_{0}^{1} k_{4}(x, t) h_{i}(t) d t
\end{aligned}
$$

Taking the collocation points $x \rightarrow x_{l}$ in equations (12), (13), (10) and (11), we obtain

$$
\sum_{i=1}^{2 M}\left[\begin{array}{cc}
h_{i}\left(x_{l}\right)-\alpha_{i}\left(x_{l}\right) & -\beta_{i}\left(x_{l}\right) \\
-\phi_{i}\left(x_{l}\right) & h_{i}\left(x_{l}\right)-\psi_{i}\left(x_{l}\right)
\end{array}\right]\left[\begin{array}{l}
a_{i} \\
b_{i}
\end{array}\right]=\left[\begin{array}{l}
f_{1}\left(x_{l}\right) \\
f_{2}\left(x_{l}\right)
\end{array}\right]
$$




$$
\begin{aligned}
& u\left(x_{l}\right)=\sum_{i=1}^{2 M} a_{i} h_{i}\left(x_{l}\right) \\
& v\left(x_{l}\right)=\sum_{i=1}^{2 M} b_{i} h_{i}\left(x_{l}\right)
\end{aligned}
$$

The wavelet coefficients $a_{i}, b_{i}, i=1,2, \ldots, 2 M$ are obtained by solving the $4 M$ system of equations in (18). These coefficients are then substituted in equations (19) and (20) to obtain the Haar wavelet solution at the collocation points $x_{l}, l=1,2, \ldots, 2 M$.

\section{Two-dimensional Coupled Fredholm Integral Equations:-}

The two-dimensional coupled Fredholm integral equations of the second kind are given by

$$
\begin{aligned}
& u(x, y)=f_{1}(x, y)+\int_{0}^{1} \int_{0}^{1} k_{1}(x, y, t, s) u(t, s) d t d s+\int_{0}^{1} \int_{0}^{1} k_{2}(x, y, t, s) v(t, s) d t d s \\
& v(x, y)=f_{2}(x, y)+\int_{0}^{1} \int_{0}^{1} k_{3}(x, y, t, s) u(t, s) d t d s+\int_{0}^{1} \int_{0}^{1} k_{4}(x, y, t, s) v(t, s) d t d s
\end{aligned}
$$

where $f_{1}(x, y), f_{2}(x, y)$ are known functions, $k_{1}(x, y, t, s), k_{2}(x, y, t, s), k_{3}(x, y, t, s), k_{4}(x, y, t, s)$ are the kernels and $u(x, y), v(x, y)$ are the unknown functions.

Let the Haar wavelet solutions be in the form

$$
\begin{aligned}
& u(x, y)=\sum_{i=1}^{2 M} \sum_{j=1}^{2 M^{*}} a_{i j} h_{i}(x) h_{j}(y) \\
& v(x, y)=\sum_{i=1}^{2 M} \sum_{j=1}^{2 M^{*}} b_{i j} h_{i}(x) h_{j}(y)
\end{aligned}
$$

Substituting equations (23) and (24) in equations (21) and (22) gives

$$
\begin{aligned}
& \sum_{i=1}^{2 M} \sum_{j=1}^{2 M^{*}}\left\{a_{i j}\left[h_{i}(x) h_{j}(y)-\alpha_{i j}(x, y)\right]-b_{i j} \beta_{i j}(x, y)\right\}=f_{1}(x, y) \\
& \sum_{i=1}^{2 M} \sum_{j=1}^{2 M^{*}}\left\{b_{i j}\left[h_{i}(x) h_{j}(y)-\psi_{i j}(x, y)\right]-a_{i j} \phi_{i j}(x, y)\right\}=f_{2}(x, y)
\end{aligned}
$$

where

$$
\begin{aligned}
& \alpha_{i j}(x, y)=\int_{0}^{1} \int_{0}^{1} k_{1}(x, y, t, s) h_{i}(t) h_{j}(s) d t d s \\
& \beta_{i j}(x, y)=\int_{0}^{1} \int_{0}^{1} k_{2}(x, y, t, s) h_{i}(t) h_{j}(s) d t d s \\
& \phi_{i j}(x, y)=\int_{0}^{1} \int_{0}^{1} k_{3}(x, y, t, s) h_{i}(t) h_{j}(s) d t d s \\
& \psi_{i j}(x, y)=\int_{0}^{1} \int_{0}^{1} k_{4}(x, y, t, s) h_{i}(t) h_{j}(s) d t d s
\end{aligned}
$$

Taking the collocation points $x \rightarrow x_{l}$ in equations (25), (26), (23) and (24), we obtain

$$
\sum_{i=1}^{2 M} \sum_{j=1}^{2 M^{*}}\left[\begin{array}{cc}
h_{i}\left(x_{l}\right) h_{j}\left(y_{n}\right)-\alpha_{i j}\left(x_{l}, y_{n}\right) & -\beta_{i j}\left(x_{l}, y_{n}\right) \\
-\phi_{i j}\left(x_{l}, y_{n}\right) & h_{i}\left(x_{l}\right) h_{j}\left(y_{n}\right)-\psi_{i j}\left(x_{l}, y_{n}\right)
\end{array}\right]\left[\begin{array}{l}
a_{i j} \\
b_{i j}
\end{array}\right]=\left[\begin{array}{l}
f_{1}\left(x_{l}, y_{n}\right) \\
f_{2}\left(x_{l}, y_{n}\right)
\end{array}\right]
$$




$$
\begin{aligned}
& u\left(x_{l}, y_{n}\right)=\sum_{i=1}^{2 M} \sum_{j=1}^{2 M^{*}} a_{i j} h_{i}\left(x_{l}\right) h_{j}\left(y_{n}\right) \\
& v\left(x_{l}, y_{n}\right)=\sum_{i=1}^{2 M} \sum_{j=1}^{2 M^{*}} b_{i j} h_{i}\left(x_{l}\right) h_{j}\left(y_{n}\right)
\end{aligned}
$$

The wavelet coefficients $a_{i j}, b_{i j}, i=1,2, \ldots, 2 M, j=1,2, \ldots, 2 M^{*}$ are obtained by solving the $4 M \times 4 M^{*}$ system of equations in (31). These coefficients are then substituted in equations (32) and (33) to obtain the Haar wavelet solution at the collocation points $\left(x_{l}, y_{n}\right), l=1,2, \ldots, 2 M, n=1,2, \ldots, 2 M^{*}$.

\section{Numerical Examples and Discussion:-}

In this section, examples are considered to check the efficiency and accuracy of the Haar wavelet collocation method (HWCM). Lagrange interpolation (in the case of one-dimensional coupled Fredholm integral equation) and Lagrange bivariate interpolation (in the case two-dimensional of coupled Fredholm integral equation) is used to find the solution at the specified points. The entire computational work has been done with the help of MATLAB software.

Example 1:

$$
\begin{gathered}
u(x)=\frac{2}{3} e^{x}-\frac{1}{4}+\frac{1}{3} \int_{0}^{1} e^{x} t u(t) d t+\frac{1}{3} \int_{0}^{1} t^{2} v(t) d t \\
v(x)=\frac{3}{2} x-x^{2}+\int_{0}^{1} x^{2} e^{-t} u(t) d t-\int_{0}^{1} x v(t) d t
\end{gathered}
$$

The exact solutions are

$$
\begin{gathered}
u(x)=e^{x} \\
v(x)=x
\end{gathered}
$$

Solving equations (14)-(17) for $\alpha_{i}(x), \beta_{i}(x), \phi_{i}(x)$ and $\psi_{i}(x)$, we obtain

$$
\begin{gathered}
\alpha_{i}(x)=\left\{\begin{array}{cc}
\frac{1}{6} e^{x} & \text { for } i=1 \\
\frac{1}{6}\left(2 \xi_{2}^{2}-\xi_{1}^{2}-\xi_{3}^{2}\right) e^{x} & \text { for } i>1
\end{array}\right. \\
\beta_{i}(x)=\left\{\begin{array}{cc}
\frac{1}{3} & \text { for } i=1 \\
\frac{1}{3}\left(2 \xi_{2}^{3}-\xi_{1}^{3}-\xi_{3}^{3}\right) & \text { for } i>1
\end{array}\right. \\
\phi_{i}(x)=\left\{\begin{array}{cc}
\left(\frac{e-1}{e}\right) x^{2} & \text { for } i=1 \\
-\left(2 e^{-\xi_{2}}-e^{-\xi_{1}}-e^{-\xi_{3}}\right) x^{2} & \text { for } i>1
\end{array}\right. \\
\psi_{i}(x)=\left\{\begin{array}{lll}
-x & \text { for } i=1 & \\
0 & \text { for } i>1 &
\end{array}\right.
\end{gathered}
$$


The HWCM solution of the example with $J=5$ are given in Table 1 and Figure 1 . The results are compared with the exact solution. If $u_{e x}(x)$ and $v_{e x}(x)$ are the exact solutions (36) and (37) respectively, we define the error estimates as

$$
\begin{gathered}
\sigma_{u}=\frac{1}{2 M}\left\|u(x)-u_{e x}(x)\right\| \\
\sigma_{v}=\frac{1}{2 M}\left\|v(x)-v_{e x}(x)\right\|
\end{gathered}
$$

We have obtained the following error estimates.

\begin{tabular}{|c|c|c|c|c|}
\hline \multirow{2}{*}{$J$} & \multicolumn{2}{|c|}{$\sigma_{u}$} & \multicolumn{2}{c|}{$\sigma_{v}$} \\
\cline { 2 - 5 } & $L_{2}$ & $L_{\infty}$ & $L_{2}$ & $L_{\infty}$ \\
\hline 3 & $3.0523 \mathrm{E}-04$ & $1.0146 \mathrm{E}-04$ & $4.5027 \mathrm{E}-05$ & $2.5134 \mathrm{E}-05$ \\
\hline 4 & $5.3993 \mathrm{E}-05$ & $1.2839 \mathrm{E}-05$ & $7.9750 \mathrm{E}-06$ & $3.2604 \mathrm{E}-06$ \\
\hline 5 & $9.5463 \mathrm{E}-06$ & $1.6145 \mathrm{E}-06$ & $1.4105 \mathrm{E}-06$ & $4.1503 \mathrm{E}-07$ \\
\hline 6 & $1.6876 \mathrm{E}-06$ & $2.0242 \mathrm{E}-07$ & $2.4937 \mathrm{E}-07$ & $5.2348 \mathrm{E}-08$ \\
\hline
\end{tabular}

\section{Example 2:}

$$
\begin{aligned}
& u(x)=\frac{5}{6} x^{2}-\frac{25}{12} x+1+\int_{0}^{1} x(1+t) u(t) d t+\int_{0}^{1} x^{2} t v(t) d t \\
& v(x)=x^{4}-\frac{1}{5} x^{2}-\frac{7}{12} x+\int_{0}^{1} x t u(t) d t+\int_{0}^{1} x(x-t) v(t) d t
\end{aligned}
$$

The exact solutions are

$$
\begin{gathered}
u(x)=x^{2}+1 \\
v(x)=x^{4}
\end{gathered}
$$

Solving equations (14)-(17) for $\alpha_{i}(x), \beta_{i}(x), \phi_{i}(x)$ and $\psi_{i}(x)$, we get

$$
\begin{gathered}
\alpha_{i}(x)=\left\{\begin{array}{cc}
\frac{3}{2} x & \text { for } i=1 \\
\frac{1}{2}\left(2 \xi_{2}^{2}-\xi_{1}^{2}-\xi_{3}^{2}\right) x & \text { for } i>1
\end{array}\right. \\
\beta_{i}(x)=\left\{\begin{array}{cc}
\frac{1}{2} x^{2} & \text { for } i=1 \\
\frac{1}{2}\left(2 \xi_{2}^{2}-\xi_{1}^{2}-\xi_{3}^{2}\right) & \text { for } i>1
\end{array}\right. \\
\phi_{i}(x)=\left\{\begin{array}{cc}
\frac{1}{2} x & \text { for } i=1 \\
\frac{1}{2}\left(2 \xi_{2}^{2}-\xi_{1}^{2}-\xi_{3}^{2}\right) x & \text { for } i>1
\end{array}\right. \\
\psi_{i}(x)=\left\{\begin{array}{cc}
x^{2}-\frac{1}{2} x & \text { for } i=1 \\
-\frac{1}{2}\left(2 \xi_{2}^{2}-\xi_{1}^{2}-\xi_{3}^{2}\right) x & \text { for } i>1
\end{array}\right.
\end{gathered}
$$


The HWCM solution of the example with $J=5$ are given in Table 2 and Figure 2 . The results are compared with the exact solution. We have obtained the following error estimates.

\begin{tabular}{|c|c|c|c|c|}
\hline \multirow{2}{*}{$J$} & \multicolumn{2}{|c|}{$\sigma_{u}$} & \multicolumn{2}{c|}{$\sigma_{v}$} \\
\cline { 2 - 5 } & $L_{2}$ & $L_{\infty}$ & $L_{2}$ & $L_{\infty}$ \\
\hline 3 & $2.3792 \mathrm{E}-03$ & $1.0344 \mathrm{E}-03$ & $8.4021 \mathrm{E}-04$ & $3.9559 \mathrm{E}-04$ \\
\hline 4 & $4.2311 \mathrm{E}-04$ & $1.3244 \mathrm{E}-04$ & $1.4950 \mathrm{E}-04$ & $5.0946 \mathrm{E}-05$ \\
\hline 5 & $7.4908 \mathrm{E}-05$ & $1.6731 \mathrm{E}-05$ & $2.6472 \mathrm{E}-05$ & $6.4540 \mathrm{E}-06$ \\
\hline 6 & $1.3247 \mathrm{E}-05$ & $2.1016 \mathrm{E}-06$ & $4.6815 \mathrm{E}-06$ & $8.1184 \mathrm{E}-07$ \\
\hline
\end{tabular}

Example 3:

$$
\begin{gathered}
u(x, y)=\frac{79}{30} x^{2}-\frac{47}{12} y^{2}+9+\int_{0}^{1} \int_{0}^{1} y^{2} s u(t, s) d t d s+\int_{0}^{1} \int_{0}^{1} x^{2} t^{2} v(t, s) d t d s \\
v(x, y)=\frac{37}{6} x^{2}-\frac{5}{24} y-\frac{29}{3} x y-\frac{17}{2}+\int_{0}^{1} \int_{0}^{1}(x y+t s) u(t, s) d t d s+\int_{0}^{1} \int_{0}^{1}\left(x^{2}-y t s\right) v(t, s) d t d s
\end{gathered}
$$

The exact solutions are

$$
\begin{gathered}
u(x, y)=x^{2}+y^{2}+9 \\
v(x, y)=x^{2}+y-6
\end{gathered}
$$

Solving equations (27)-(30) for $\alpha_{i j}(x, y), \beta_{i j}(x, y), \phi_{i j}(x, y)$ and $\psi_{i j}(x, y)$, we obtain

$$
\begin{gathered}
\alpha_{i j}(x, y)=\left\{\begin{array}{cc}
\frac{1}{2} y^{2} & \text { for } i=1, j=1 \\
\frac{1}{2}\left(2 \eta_{2}^{2}-\eta_{1}^{2}-\eta_{3}^{2}\right) y^{2} & \text { for } i=1, j>1 \\
0 & \text { for } i>1, j=1 \\
0 & \text { for } i>1, j>1
\end{array}\right. \\
\beta_{i j}(x, y)=\left\{\begin{array}{cc}
\frac{1}{3} x^{2} & \text { for } i=1, j=1 \\
0 & \text { for } i=1, j>1 \\
\frac{1}{3}\left(2 \xi_{2}^{3}-\xi_{1}^{3}-\xi_{3}^{3}\right) x^{2} & \text { for } i>1, j=1 \\
0 & \text { for } i>1, j>1
\end{array}\right. \\
\frac{1}{4}\left(2 \eta_{2}^{2}-\eta_{1}^{2}-\eta_{3}^{2}\right) \\
\frac{1}{4}\left(2 \xi_{2}^{2}-\xi_{1}^{2}-\xi_{3}^{2}\right) \\
\frac{1}{4}\left(2 \xi_{2}^{2}-\xi_{1}^{2}-\xi_{3}^{2}\right)\left(2 \eta_{2}^{2}-\eta_{1}^{2}-\eta_{3}^{2}\right)
\end{gathered}
$$




$$
\psi_{i j}(x, y)=\left\{\begin{array}{cc}
x^{2}-\frac{1}{4} y & \text { for } i=1, j=1 \\
-\frac{1}{4}\left(2 \eta_{2}^{2}-\eta_{1}^{2}-\eta_{3}^{2}\right) y & \text { for } i=1, j>1 \\
-\frac{1}{4}\left(2 \xi_{2}^{2}-\xi_{1}^{2}-\xi_{3}^{2}\right) y & \text { for } i>1, j=1 \\
-\frac{1}{4}\left(2 \xi_{2}^{2}-\xi_{1}^{2}-\xi_{3}^{2}\right)\left(2 \eta_{2}^{2}-\eta_{1}^{2}-\eta_{3}^{2}\right) y & \text { for } i>1, j>1
\end{array}\right.
$$

The HWCM solution of the example with $J=J^{*}=5$ are given in Tables 3,4 and Figures 3,5. The results are compared with the exact solution. Figures 4,6 show the physical behavior of the HWCM solution in contour and 3D. If $u_{e x}(x)$ and $v_{e x}(x)$ are the exact solutions (36) and (37) respectively, we define the error estimates as

$$
\begin{aligned}
& \mu_{u}=\frac{1}{2 M * 2 M^{*}}\left\|u(x, y)-u_{e x}(x, y)\right\| \\
& \mu_{v}=\frac{1}{2 M * 2 M^{*}}\left\|v(x, y)-v_{e x}(x, y)\right\|
\end{aligned}
$$

We have obtained the following error estimates.

\begin{tabular}{|c|c|c|c|c|c|}
\hline \multirow{2}{*}{$J$} & \multirow{2}{*}{$J^{*}$} & \multicolumn{2}{|c|}{$\mu_{u}$} & \multicolumn{2}{c|}{$\mu_{v}$} \\
\cline { 3 - 6 } & & $L_{2}$ & $L_{\infty}$ & $L_{2}$ & $L_{\infty}$ \\
\hline 2 & 2 & $4.3917 \mathrm{E}-04$ & $6.8854 \mathrm{E}-04$ & $6.9712 \mathrm{E}-04$ & $1.1937 \mathrm{E}-03$ \\
\hline 3 & 3 & $5.5392 \mathrm{E}-05$ & $9.0884 \mathrm{E}-05$ & $8.7714 \mathrm{E}-05$ & $1.5703 \mathrm{E}-04$ \\
\hline 4 & 4 & $6.9395 \mathrm{E}-06$ & $1.1653 \mathrm{E}-05$ & $1.0982 \mathrm{E}-05$ & $2.0108 \mathrm{E}-05$ \\
\hline 5 & 5 & $8.6793 \mathrm{E}-07$ & $1.4745 \mathrm{E}-06$ & $1.3733 \mathrm{E}-06$ & $2.5432 \mathrm{E}-06$ \\
\hline
\end{tabular}

\section{Example 4:}

$$
\begin{gathered}
u(x, y)=x^{2}+y^{4}-\frac{5}{24} e^{x} y^{2}-\frac{17}{120}+\int_{0}^{1} \int_{0}^{1} e^{x} y^{2} s^{3} u(t, s) d t d s+\int_{0}^{1} \int_{0}^{1} t s v(t, s) d t d s \\
v(x, y)=x y^{6}+y^{3}-\frac{2}{9} y-\frac{4}{15} e^{x}+\int_{0}^{1} \int_{0}^{1} e^{x} t^{2} u(t, s) d t d s+\int_{0}^{1} \int_{0}^{1} y s^{2} v(t, s) d t d s
\end{gathered}
$$

The exact solutions are

$$
\begin{gathered}
u(x, y)=x^{2}+y^{4} \\
v(x, y)=x y^{6}+y^{3}
\end{gathered}
$$

Solving equations (27)-(30) for $\alpha_{i j}(x, y), \beta_{i j}(x, y), \phi_{i j}(x, y)$ and $\psi_{i j}(x, y)$, we get

$$
\alpha_{i j}(x, y)=\left\{\begin{array}{cc}
\frac{1}{4} e^{x} y^{2} & \text { for } i=1, j=1 \\
\frac{1}{4}\left(2 \eta_{2}^{4}-\eta_{1}^{4}-\eta_{3}^{4}\right) e^{x} y^{2} & \text { for } i=1, j>1 \\
0 & \text { for } i>1, j=1 \\
0 & \text { for } i>1, j>1
\end{array}\right.
$$




$$
\beta_{i j}(x, y)=\left\{\begin{array}{cc}
\frac{1}{4} & \text { for } i=1, j=1 \\
\frac{1}{4}\left(2 \eta_{2}^{2}-\eta_{1}^{2}-\eta_{3}^{2}\right) & \text { for } i=1, j>1 \\
\frac{1}{4}\left(2 \xi_{2}^{2}-\xi_{1}^{2}-\xi_{3}^{2}\right) & \text { for } i>1, j=1 \\
\frac{1}{4}\left(2 \xi_{2}^{2}-\xi_{1}^{2}-\xi_{3}^{2}\right)\left(2 \eta_{2}^{2}-\eta_{1}^{2}-\eta_{3}^{2}\right) & \text { for } i>1, j>1
\end{array}\right.
$$

$$
\begin{aligned}
& \phi_{i j}(x, y)=\left\{\begin{array}{cc}
\frac{1}{3} e^{x} & \text { for } i=1, j=1 \\
0 & \text { for } i=1, j>1 \\
\frac{1}{3}\left(2 \xi_{2}^{3}-\xi_{1}^{3}-\xi_{3}^{3}\right) e^{x} & \text { for } i>1, j=1 \\
0 & \text { for } i>1, j>1
\end{array}\right. \\
& \psi_{i j}(x, y)=\left\{\begin{array}{cc}
\frac{1}{3} y & \text { for } i=1, j=1 \\
\frac{1}{3}\left(2 \eta_{2}^{3}-\eta_{1}^{3}-\eta_{3}^{3}\right) y & \text { for } i=1, j>1 \\
0 & \text { for } i>1, j=1 \\
0 & \text { for } i>1, j>1
\end{array}\right.
\end{aligned}
$$

The HWCM solution of the example with $J=J^{*}=5$ are given in Tables 5,6 and Figures 7,9. The results are compared with the exact solution. Figures 8,10 show the physical behavior of the HWCM solution in contour and 3D. We have obtained the following error estimates.

\begin{tabular}{|c|c|c|c|c|c|}
\hline \multirow{2}{*}{$J$} & \multirow{2}{*}{$J^{*}$} & \multicolumn{2}{|c|}{$\mu_{u}$} & \multicolumn{2}{c|}{$\mu_{v}$} \\
\cline { 3 - 6 } & & $L_{2}$ & $L_{\infty}$ & $L_{2}$ & $L_{\infty}$ \\
\hline 2 & 2 & $1.9150 \mathrm{E}-03$ & $2.1278 \mathrm{E}-03$ & $2.7128 \mathrm{E}-03$ & $3.4901 \mathrm{E}-03$ \\
\hline 3 & 3 & $2.4283 \mathrm{E}-04$ & $2.7354 \mathrm{E}-04$ & $3.4289 \mathrm{E}-04$ & $4.5139 \mathrm{E}-04$ \\
\hline 4 & 4 & $3.0463 \mathrm{E}-05$ & $3.4560 \mathrm{E}-05$ & $4.2981 \mathrm{E}-05$ & $5.7251 \mathrm{E}-05$ \\
\hline 5 & 5 & $3.8113 \mathrm{E}-06$ & $4.3396 \mathrm{E}-06$ & $5.3764 \mathrm{E}-06$ & $7.2041 \mathrm{E}-06$ \\
\hline
\end{tabular}

\section{Conclusion:-}

In this paper, an efficient numerical scheme based on uniform Haar wavelets is used to solve one-dimensional and two-dimensional coupled Fredholm integral equations of second kind. The numerical scheme is tested for four examples. The obtained numerical results are compared with the exact solutions. We observe that the error values are negligibly small which indicate that the HWCM solution is very close to the exact solution. Thus the Haar wavelet method guarantees the necessary accuracy with a small number of grid points and a wide class of integral equations can be solved using this approach. 

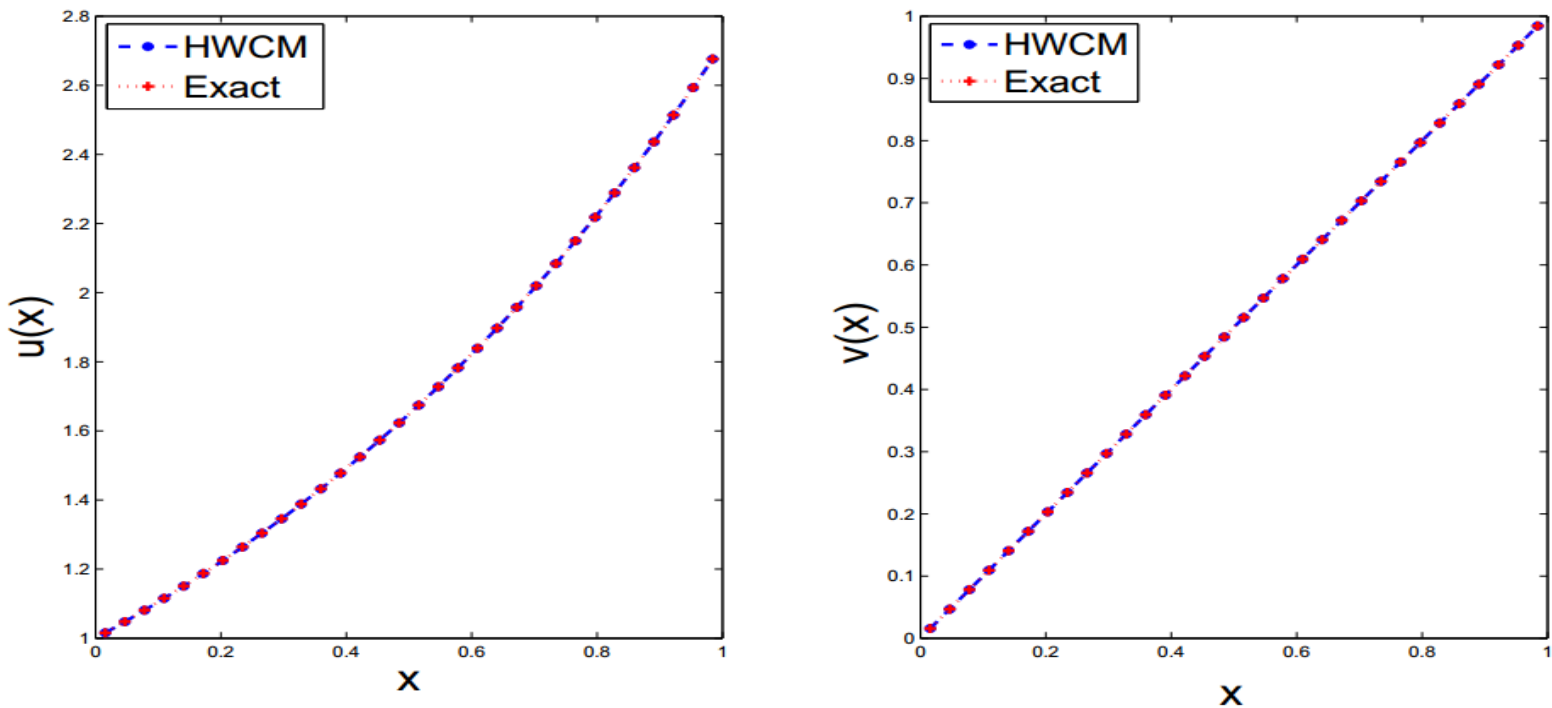

Figure 1:- Comparison of the HWCM solution and exact solution of Example 1
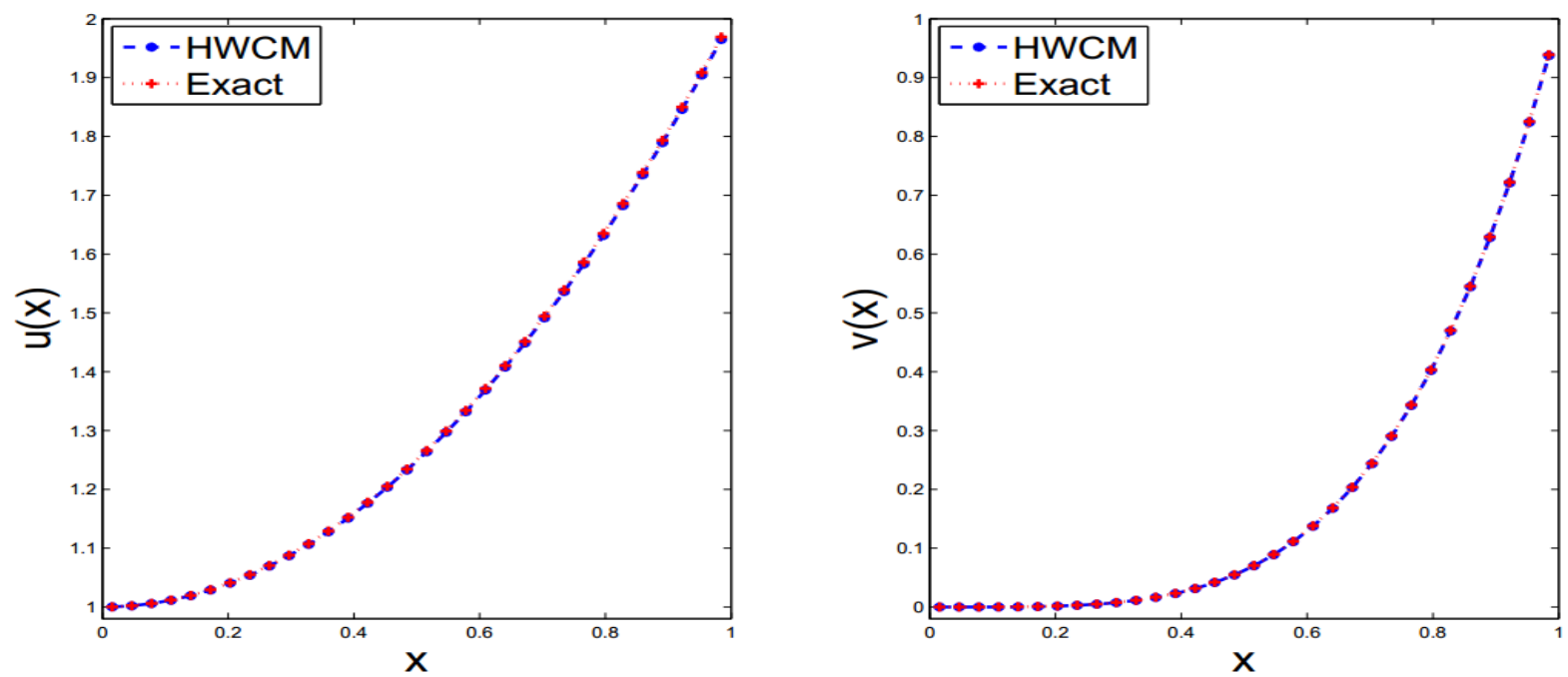

Figure 2:- Comparison of the HWCM solution and exact solution of Example 2

Table 1:- Comparison of the HWCM solution and exact solution of Example 1

\begin{tabular}{|c|c|c|c|c|}
\hline \multirow{2}{*}{$x$} & \multicolumn{2}{|c|}{$u(x)$} & \multicolumn{2}{c|}{$v(x)$} \\
\cline { 2 - 5 } & HWCM & Exact & HWCM & Exact \\
\hline 0.1 & 1.10511384 & 1.10517092 & 0.10000047 & 0.10000000 \\
\hline 0.2 & 1.22134209 & 1.22140276 & 0.20000015 & 0.20000000 \\
\hline 0.3 & 1.34979442 & 1.34985881 & 0.29999919 & 0.30000000 \\
\hline 0.4 & 1.49175621 & 1.49182470 & 0.39999753 & 0.40000000 \\
\hline 0.5 & 1.64864825 & 1.64872127 & 0.49999517 & 0.50000000 \\
\hline 0.6 & 1.82204076 & 1.82211880 & 0.59999212 & 0.60000000 \\
\hline 0.7 & 2.01366913 & 2.01375271 & 0.69998837 & 0.70000000 \\
\hline 0.8 & 2.22545123 & 2.22554093 & 0.79998393 & 0.80000000 \\
\hline 0.9 & 2.45950666 & 2.45960311 & 0.89997882 & 0.90000000 \\
\hline
\end{tabular}


Table 2:- Comparison of the HWCM solution and exact solution of Example 2

\begin{tabular}{|c|c|c|c|c|}
\hline \multirow{2}{*}{$x$} & \multicolumn{2}{|c|}{$u(x)$} & \multicolumn{2}{c|}{$v(x)$} \\
\cline { 2 - 5 } & HWCM & Exact & HWCM & Exact \\
\hline 0.1 & 1.00990756 & 1.01000000 & 0.00007747 & 0.00010000 \\
\hline 0.2 & 1.03981147 & 1.04000000 & 0.00155065 & 0.00160000 \\
\hline 0.3 & 1.08971203 & 1.09000000 & 0.00801955 & 0.00810000 \\
\hline 0.4 & 1.15960914 & 1.16000000 & 0.02548417 & 0.02560000 \\
\hline 0.5 & 1.24950281 & 1.25000000 & 0.06234451 & 0.06250000 \\
\hline 0.6 & 1.35939304 & 1.36000000 & 0.12940057 & 0.12960000 \\
\hline 0.7 & 1.48927981 & 1.49000000 & 0.23985236 & 0.24010000 \\
\hline 0.8 & 1.63916314 & 1.64000000 & 0.40929986 & 0.40960000 \\
\hline 0.9 & 1.80904312 & 1.81000000 & 0.65574309 & 0.65610000 \\
\hline
\end{tabular}
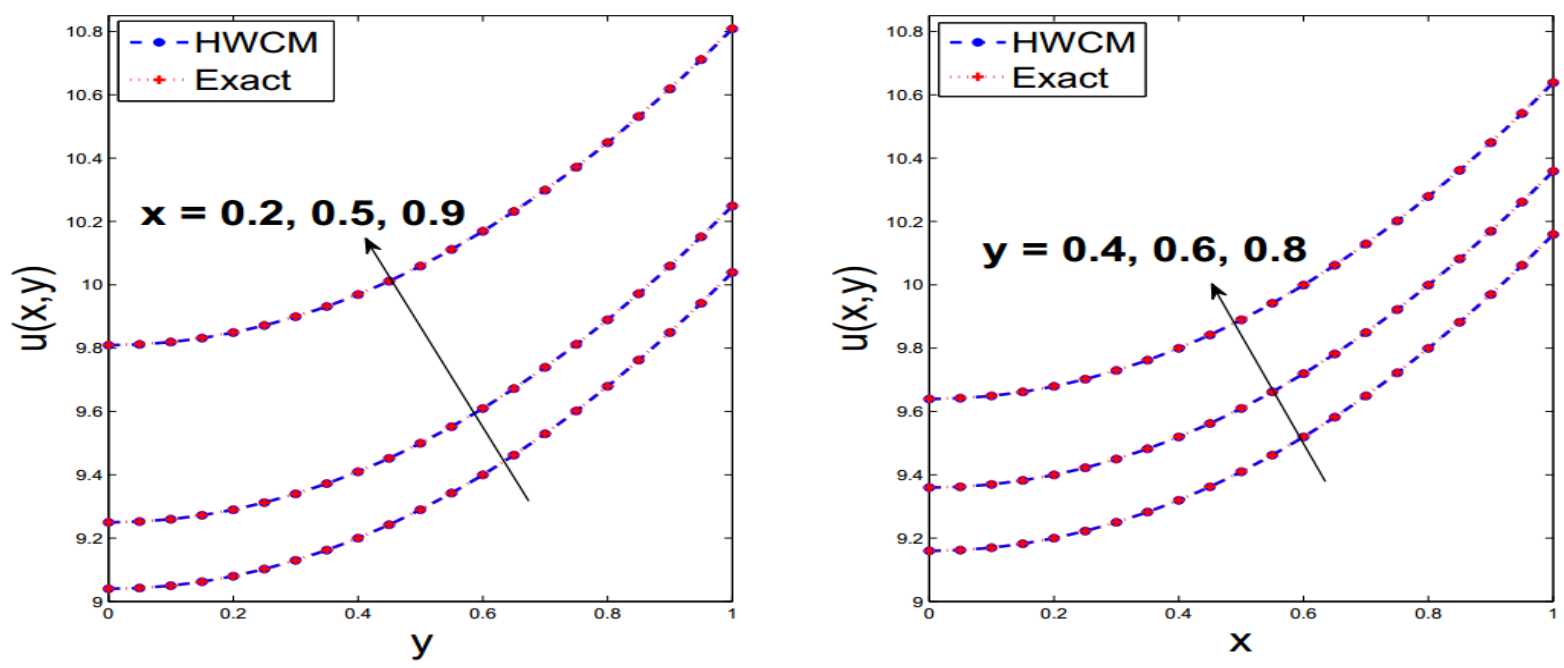

Figure 3:- Comparison of the HWCM solution and exact solution of $u(x, y)$ of Example 3
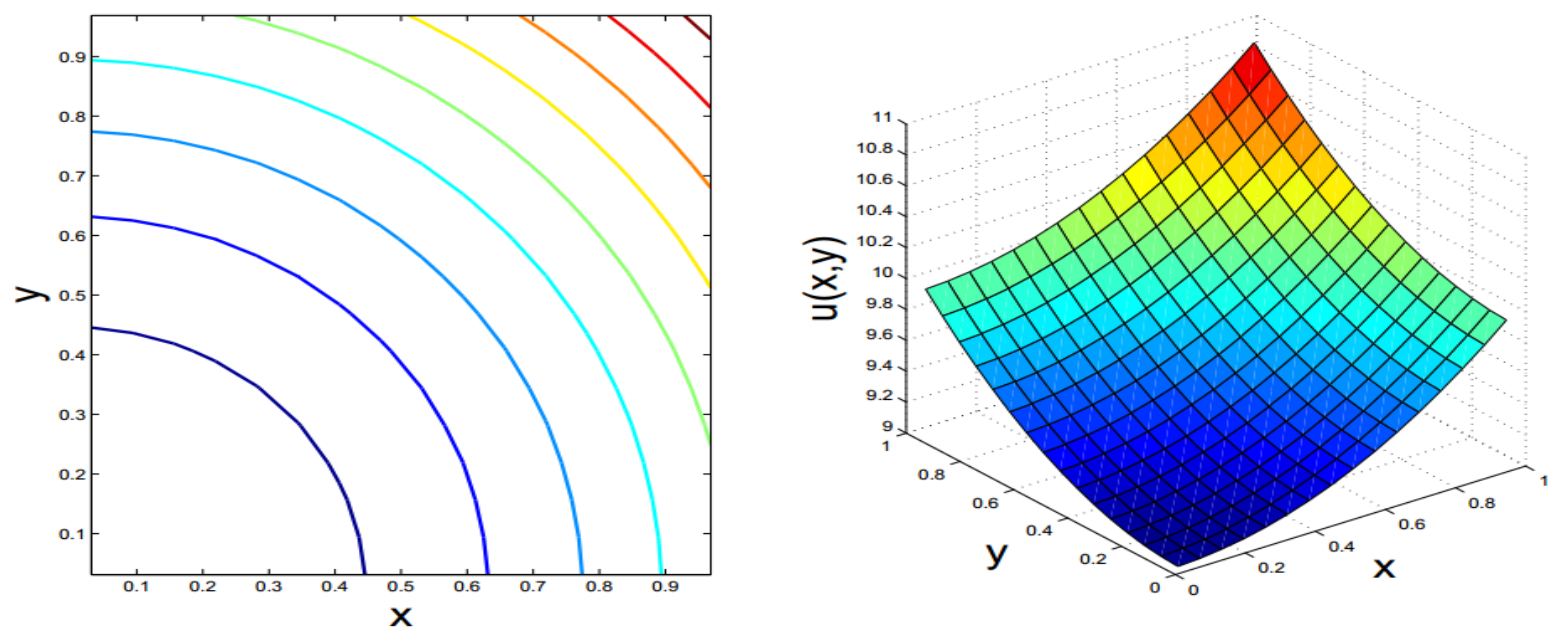

Figure 4:- Physical behaviour of the HWCM solution of $u(x, y)$ of Example 3 
Table 3:- Comparison of the HWCM solution and exact solution of $u(x, y)$ of Example 3

\begin{tabular}{|c|c|c|c|c|c|}
\hline \multirow{2}{*}{$(x, y)$} & \multicolumn{2}{|c|}{$u(x, y)$} & \multirow{2}{*}{$(x, y)$} & \multicolumn{2}{c|}{$u(x, y)$} \\
\cline { 6 - 6 } \cline { 5 - 5 } & HWCM & Exact & & HWCM & Exact \\
\hline$(0.1,0.2)$ & 9.04998588 & 9.05000000 & $(0.5,0.6)$ & 9.60995669 & 9.61000000 \\
\hline$(0.1,0.4)$ & 9.16999165 & 9.17000000 & $(0.5,0.8)$ & 9.88993701 & 9.89000000 \\
\hline$(0.1,0.6)$ & 9.36997505 & 9.37000000 & $(0.7,0.2)$ & 9.52996187 & 9.53000000 \\
\hline$(0.1,0.8)$ & 9.64697660 & 9.65000000 & $(0.7,0.4)$ & 9.64995344 & 9.65000000 \\
\hline$(0.3,0.2)$ & 9.12999070 & 9.13000000 & $(0.7,0.6)$ & 9.84993939 & 9.85000000 \\
\hline$(0.3,0.4)$ & 9.24998227 & 9.25000000 & $(0.7,0.8)$ & 10.12991971 & 10.13000000 \\
\hline$(0.3,0.6)$ & 9.44996822 & 9.45000000 & $(0.9,0.2)$ & 9.84809961 & 9.85000000 \\
\hline$(0.3,0.8)$ & 9.72994854 & 9.73000000 & $(0.9,0.4)$ & 9.96992817 & 9.97000000 \\
\hline$(0.5,0.2)$ & 9.28997917 & 9.29000000 & $(0.9,0.6)$ & 10.16991646 & 10.17000000 \\
\hline$(0.5,0.4)$ & 9.40997074 & 9.41000000 & $(0.9,0.8)$ & 10.45558830 & 10.45000000 \\
\hline
\end{tabular}
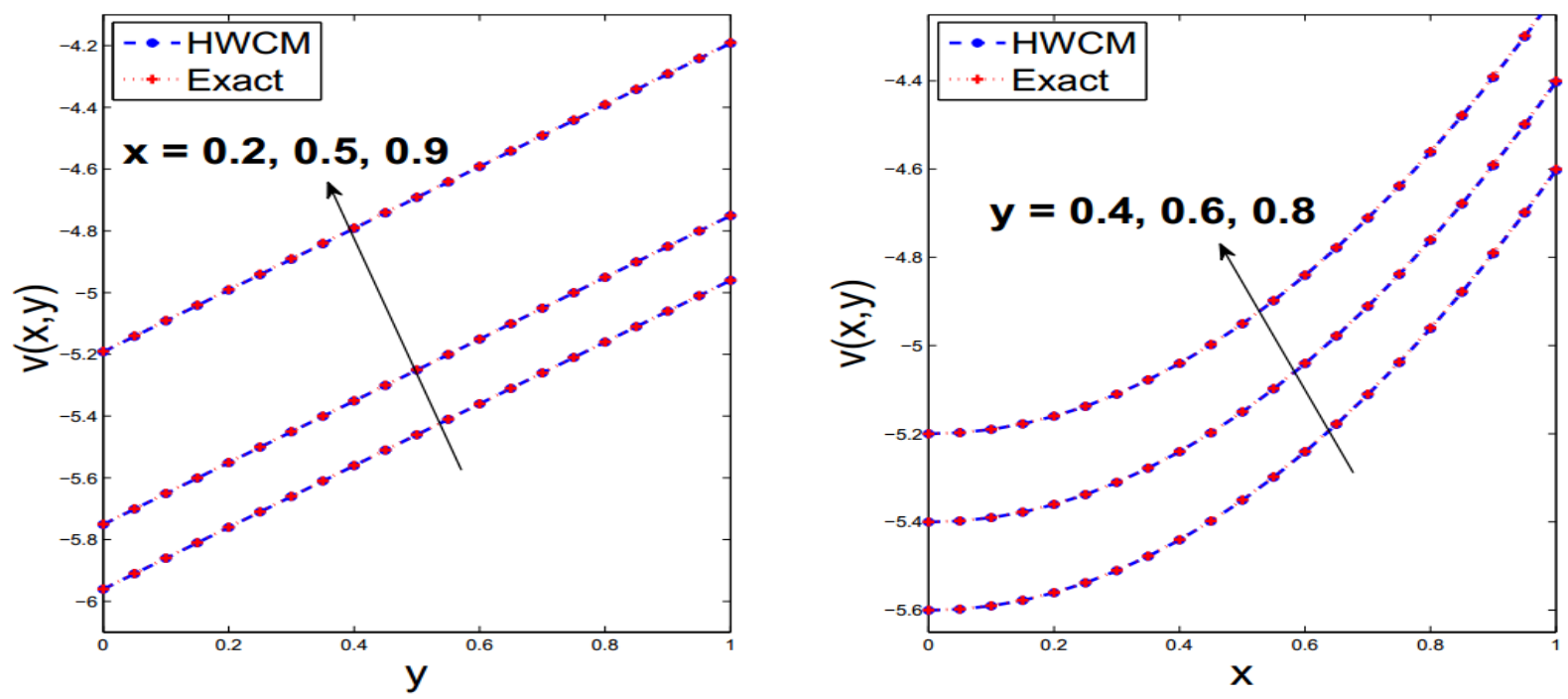

Figure 5:- Comparison of the HWCM solution and exact solution of $v(x, y)$ of Example 3
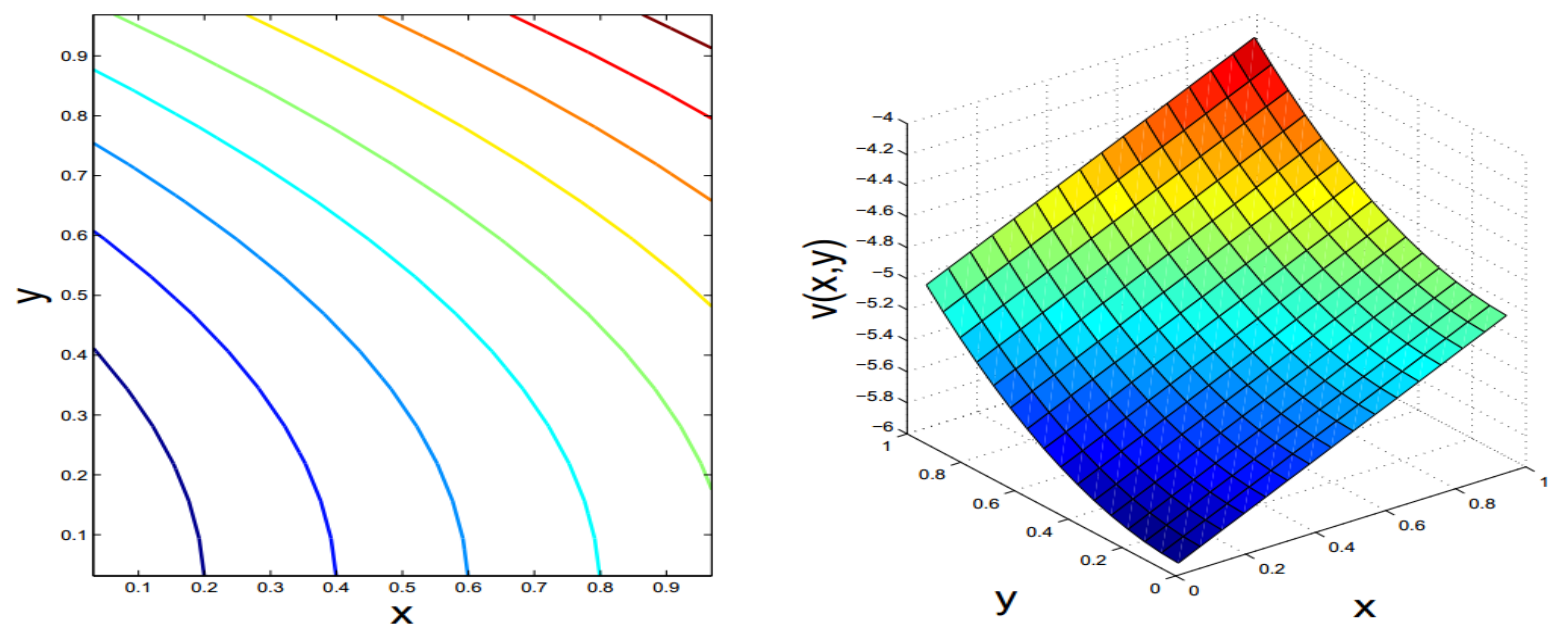

Figure 6:- Physical behaviour of the HWCM solution of $v(x, y)$ of Example 3 
Table 4:- Comparison of the HWCM solution and exact solution of $v(x, y)$ of Example 3

\begin{tabular}{|c|c|c|c|c|c|}
\hline \multirow{2}{*}{$(x, y)$} & \multicolumn{2}{|c|}{$v(x, y)$} & \multirow{2}{*}{$(x, y)$} & \multicolumn{2}{c|}{$v(x, y)$} \\
\cline { 2 - 3 } \cline { 5 - 5 } & HWCM & Exact & & HWCM & Exact \\
\hline$(0.1,0.2)$ & -5.79016334 & -5.79000000 & $(0.5,0.6)$ & -5.15006858 & -5.15000000 \\
\hline$(0.1,0.4)$ & -5.59003194 & -5.59000000 & $(0.5,0.8)$ & -4.95006719 & -4.95000000 \\
\hline$(0.1,0.6)$ & -5.39002234 & -5.39000000 & $(0.7,0.2)$ & -5.31009835 & -5.31000000 \\
\hline$(0.1,0.8)$ & -5.17753288 & -5.19000000 & $(0.7,0.4)$ & -5.11010048 & -5.11000000 \\
\hline$(0.3,0.2)$ & -5.71005219 & -5.71000000 & $(0.7,0.6)$ & -4.91010262 & -4.91000000 \\
\hline$(0.3,0.4)$ & -5.51004728 & -5.51000000 & $(0.7,0.8)$ & -4.71010475 & -4.71000000 \\
\hline$(0.3,0.6)$ & -5.31004236 & -5.31000000 & $(0.9,0.2)$ & -4.97761272 & -4.99000000 \\
\hline$(0.3,0.8)$ & -5.11003745 & -5.11000000 & $(0.9,0.4)$ & -4.79014010 & -4.79000000 \\
\hline$(0.5,0.2)$ & -5.55007136 & -5.55000000 & $(0.9,0.6)$ & -4.59014657 & -4.59000000 \\
\hline$(0.5,0.4)$ & -5.35006997 & -5.35000000 & $(0.9,0.8)$ & -4.40064483 & -4.39000000 \\
\hline
\end{tabular}
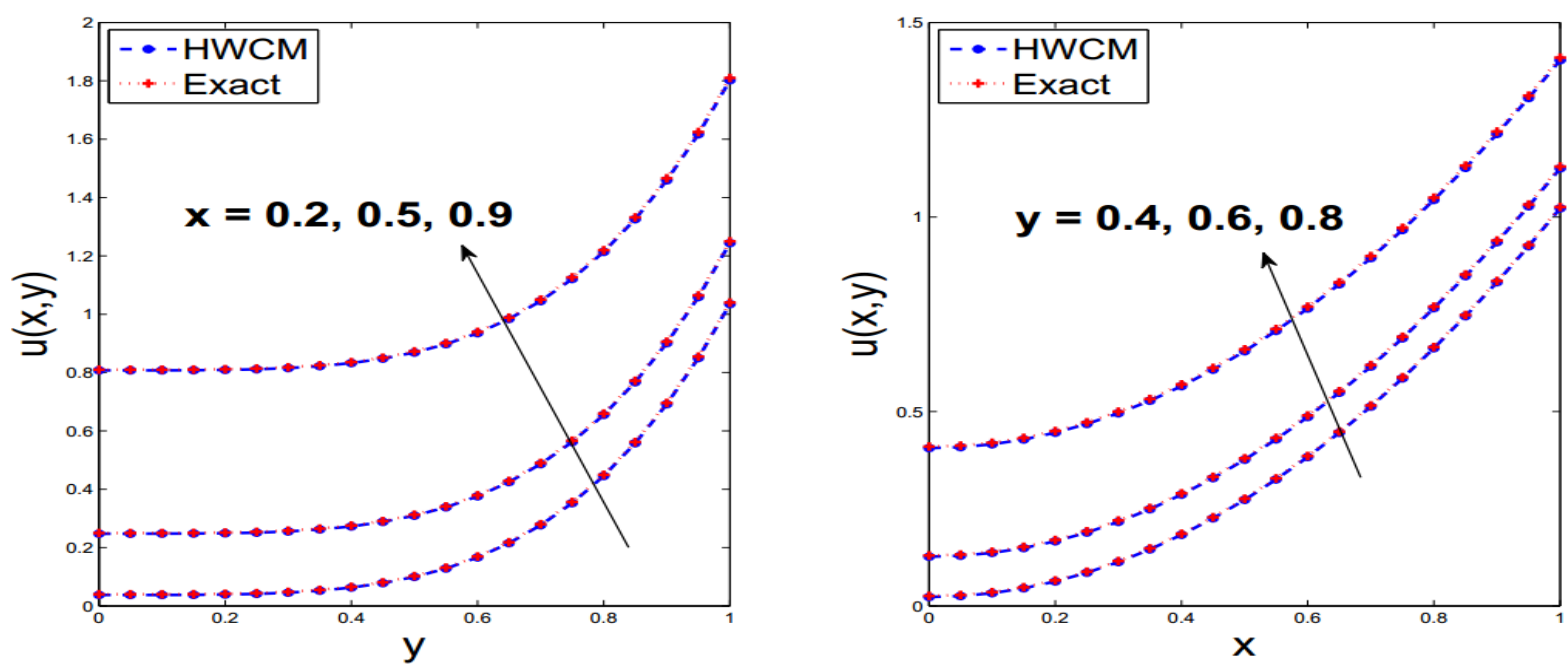

Figure 7:- Comparison of the HWCM solution and exact solution of $u(x, y)$ of Example 4
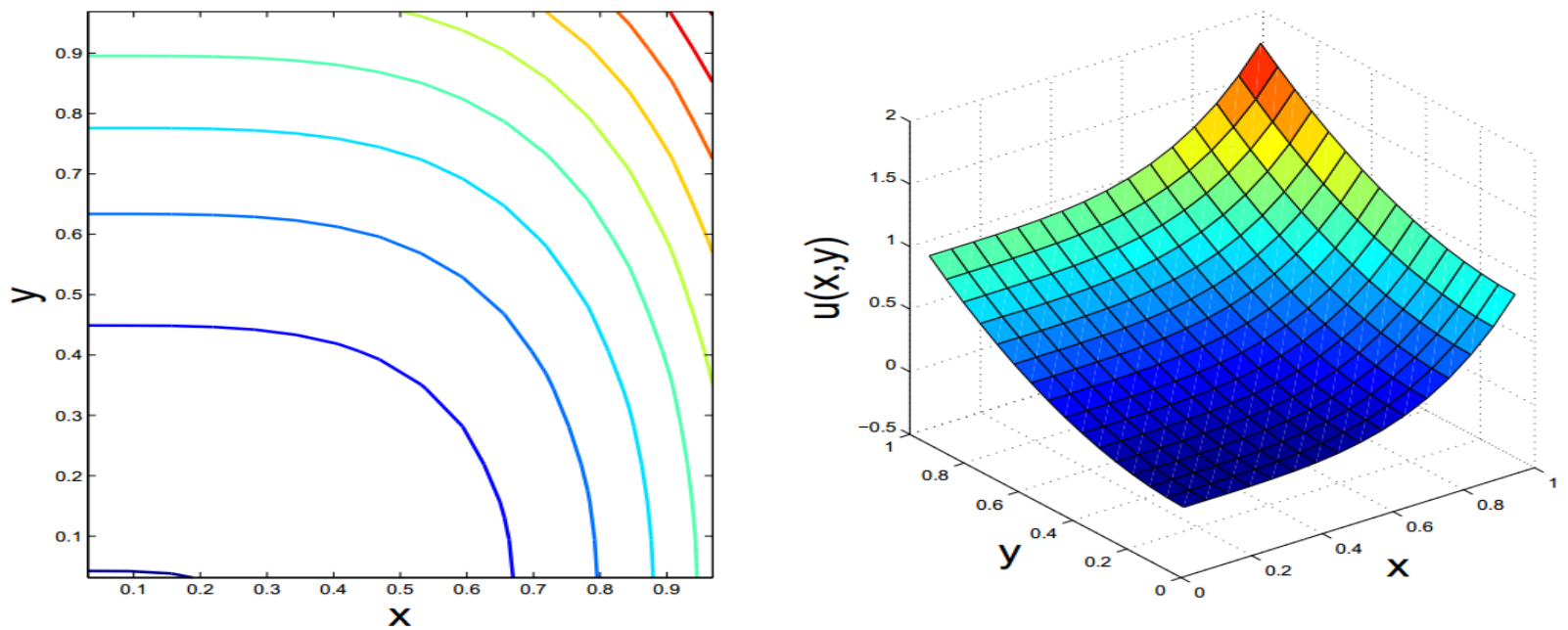

Figure 8:- Physical behaviour of the HWCM solution of $u(x, y)$ of Example 4 
Table 5:- Comparison of the HWCM solution and exact solution of $u(x, y)$ of Example 4

\begin{tabular}{|c|c|c|c|c|c|}
\hline \multirow{2}{*}{$(x, y)$} & \multicolumn{2}{|c|}{$u(x, y)$} & \multirow{2}{*}{$(x, y)$} & \multicolumn{2}{c|}{$u(x, y)$} \\
\cline { 2 - 3 } \cline { 5 - 5 } & HWCM & Exact & & HWCM & Exact \\
\hline$(0.1,0.2)$ & 0.01140846 & 0.01160000 & $(0.5,0.6)$ & 0.37936638 & 0.37960000 \\
\hline$(0.1,0.4)$ & 0.03542650 & 0.03560000 & $(0.5,0.8)$ & 0.65929971 & 0.65960000 \\
\hline$(0.1,0.6)$ & 0.13939463 & 0.13960000 & $(0.7,0.2)$ & 0.49144048 & 0.49160000 \\
\hline$(0.1,0.8)$ & 0.41937599 & 0.41960000 & $(0.7,0.4)$ & 0.51540557 & 0.51560000 \\
\hline$(0.3,0.2)$ & 0.09144431 & 0.09160000 & $(0.7,0.6)$ & 0.61934740 & 0.61960000 \\
\hline$(0.3,0.4)$ & 0.11542092 & 0.11560000 & $(0.7,0.8)$ & 0.89926596 & 0.89960000 \\
\hline$(0.3,0.6)$ & 0.21938192 & 0.21960000 & $(0.9,0.2)$ & 0.81142284 & 0.81160000 \\
\hline$(0.3,0.8)$ & 0.49932733 & 0.49960000 & $(0.9,0.4)$ & 0.83539537 & 0.83560000 \\
\hline$(0.5,0.2)$ & 0.25144259 & 0.25160000 & $(0.9,0.6)$ & 0.93932430 & 0.93960000 \\
\hline$(0.5,0.4)$ & 0.27541401 & 0.27560000 & $(0.9,0.8)$ & 1.21925107 & 1.21960000 \\
\hline
\end{tabular}
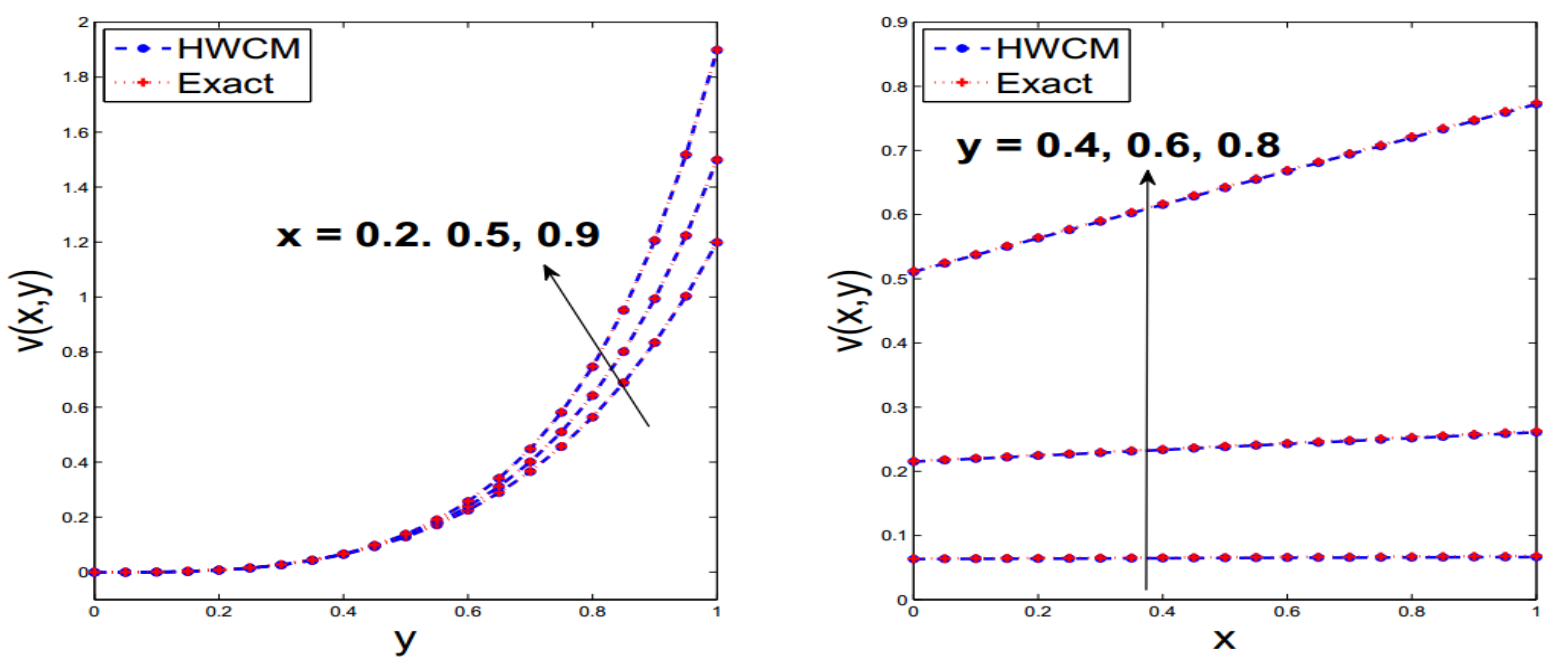

Figure 9:- Comparison of the HWCM solution and exact solution of $v(x, y)$ of Example 4
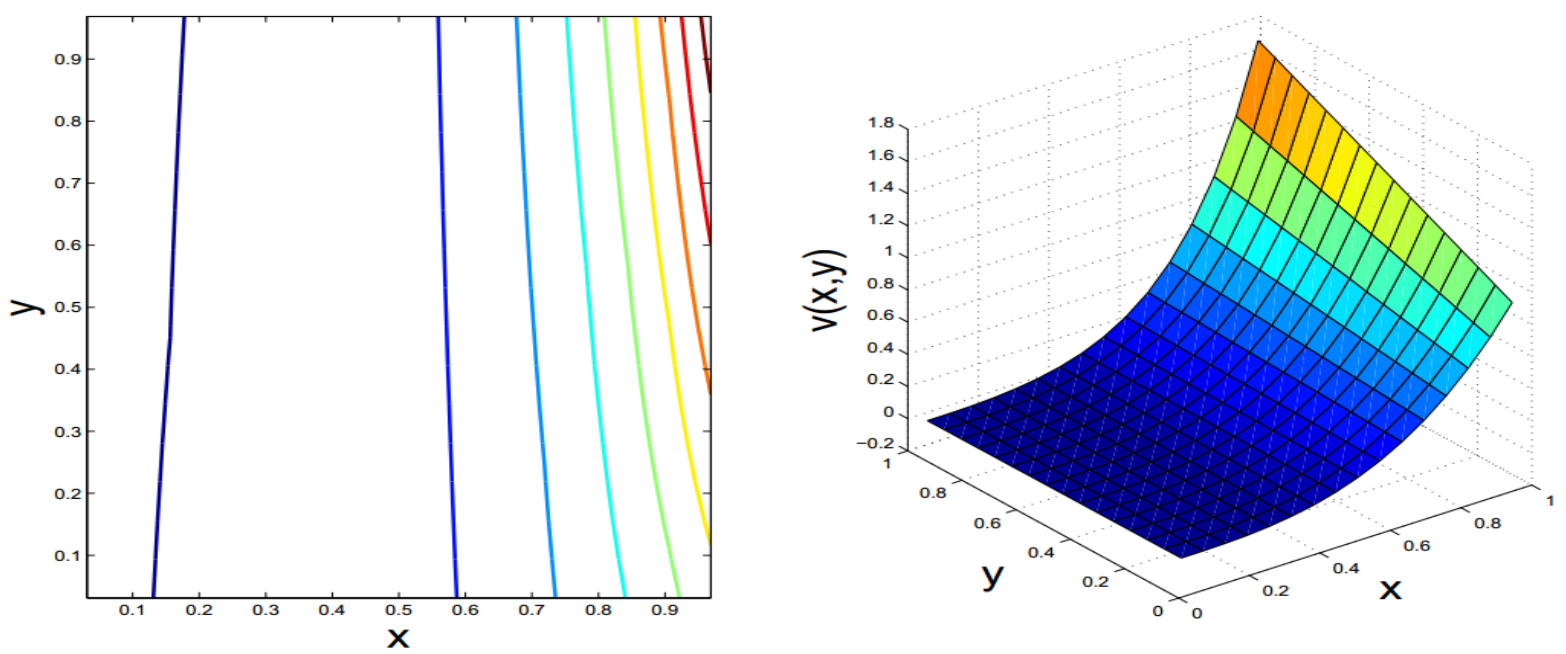

Figure 10:- Physical behaviour of the HWCM solution of $v(x, y)$ of Example 4 
Table 6:- Comparison of the HWCM solution and exact solution of $v(x, y)$ of Example 4

\begin{tabular}{|c|c|c|c|c|c|}
\hline \multirow{2}{*}{$(x, y)$} & \multicolumn{2}{|c|}{$v(x, y)$} & \multirow{2}{*}{$(x, y)$} & \multicolumn{2}{c|}{$v(x, y)$} \\
\cline { 2 - 3 } \cline { 5 - 5 } & HWCM & Exact & & HWCM & Exact \\
\hline$(0.1,0.2)$ & 0.00780355 & 0.00800640 & $(0.5,0.6)$ & 0.23898327 & 0.23932800 \\
\hline$(0.1,0.4)$ & 0.06417906 & 0.06440960 & $(0.5,0.8)$ & 0.64268455 & 0.64307200 \\
\hline$(0.1,0.6)$ & 0.22039233 & 0.22066560 & $(0.7,0.2)$ & 0.00773758 & 0.00804480 \\
\hline$(0.1,0.8)$ & 0.53791259 & 0.53821440 & $(0.7,0.4)$ & 0.06651726 & 0.06686720 \\
\hline$(0.3,0.2)$ & 0.00779918 & 0.00801920 & $(0.7,0.6)$ & 0.24826653 & 0.24865920 \\
\hline$(0.3,0.4)$ & 0.06496605 & 0.06522880 & $(0.7,0.8)$ & 0.69506540 & 0.69550080 \\
\hline$(0.3,0.6)$ & 0.22969133 & 0.22999680 & $(0.9,0.2)$ & 0.00775475 & 0.00805760 \\
\hline$(0.3,0.8)$ & 0.59029500 & 0.59064320 & $(0.9,0.4)$ & 0.06727784 & 0.06768640 \\
\hline$(0.5,0.2)$ & 0.00777273 & 0.00803200 & $(0.9,0.6)$ & 0.25753915 & 0.25799040 \\
\hline$(0.5,0.4)$ & 0.06574600 & 0.06604800 & $(0.9,0.8)$ & 0.74739349 & 0.74792960 \\
\hline
\end{tabular}

\section{References:-}

1. E. Babolian, M. Mordad, A numerical method for solving systems of linear and nonlinear integral equations of the second kind by hat basis functions, Comp. Math. Appl. 62 (2011)187-198.

2. H. Khalil, R.A. Khan, New operational matrix of integrations and coupled system of Fredholm integral equations, Chin. J. Math. 2014 (2014).

3. J. Rashidinia, M. Zarebnia, Convergence of approximate solution of system of Fredholm integral equations, J. Math. Anal. Appl. 333 (2007) 1216-1227.

4. K. Maleknejad, K. Nouri, L. Torkzadeh, Comparison projection method with Adomian's decomposition method for solving system of integral equations, Bull. Malays. Math. Sci. Soc. 34(2) (2011) 379-388.

5. G.H. Ibraheem, Solving system of linear Fredholm integral equations of second kind using open Newton-Cotes formulas, IBN Al-Haitham J. Pure Appl. Sci. 24(2) (2011).

6. P.K. Sahu, S.S. Ray, Numerical solutions for the system of Fredholm integral equations of second kind by a new approach involving semiorthogonal B-spline wavelet collocation method, Appl. Math. Comput. 234 (2014) 368-379.

7. A.R. Vahidi, T. Damercheli, A modified ADM for solving systems of linear Fredholm integral equations of the second kind, Appl. Math. Sci. 6(26) (2012) 1267-1263.

8. N. Ebrahimi, J. Rashidinia, Spline collocation for solving system of Fredholm and Volterra integral equations, Int. J. Math. Comput. Phys. Elec. Comp. Eng. 8(6) (2014) 1008-1012.

9. R.J. Hanson, J.L. Phillips, Numerical solution of two-dimensional integral equations using linear elements, SIAM J. Numer. Anal. 15(1) (2006) 113-121.

10. V. Carutasu, Numerical solution of two-dimensional nonlinear Fredholm integral equations of the second kind by spline functions, Gen. Math. 9(1-2) (2001) 31-48.

11. G. Han, R. Wang, Richardson extrapolation of iterated discrete Galerkin solution for two-dimensional Fredholm integral equations, J. Comput. Appl. Math. 139 (2002) 49-63.

12. A.S. Ismail, On the numerical solution of two-dimensional singular integral equation, Appl. Math. Comput. 173(1) (2006) 389-393.

13. R.K. Saeed, M.H. Mahmud, Solution of a system of two-dimensional linear Fredholm integral equation of the second kind by quadrature methods, Aus. J. Basic Appl. Sci 3(3) (2009) 1701-1715.

14. R.S. Sumana, L.N. Achala, A short report on different wavelets and their structures, Int. J. Res. Engg. Sci. 4(2) (2016) 31-35.

15. U. Lepik, H. Hein, Haar wavelets with applications, Springer, 2014. 